\title{
Overview of Jet Noise Measurement at JAXA*
}

\author{
By Tatsuya ISHII, ${ }^{1)}$ Kazuomi YAmAмото, ${ }^{1)}$ Kenichiro NAGAI $^{1)}$ and Yutaka ISHII ${ }^{2)}$ \\ 1) Japan Aerospace Exploration Agency, Tokyo, Japan \\ 2) Bruel and Kjaer Japan, Tokyo, Japan
}

(Received January 21st, 2014)

\begin{abstract}
This paper describes jet noise measurement recently conducted at the Japan Aerospace Exploration Agency (JAXA). Measurement techniques with regard to jet noise are of great importance for better understanding the noise generation mechanism and evaluating noise suppression characteristics of jet noise suppressors. As jet noise is influenced by the flow structure behind the nozzle, noise-related measurement should be done from various points of view. In attempting to satisfy these requirements, JAXA focused on three aspects of jet noise-related measurement: 1) the far-field sound properties, which the nozzle and subsequent jet provide; 2 ) the near-field sound sources formed primarily by the aerodynamic process; and 3 ) the flow profiles such as pressure and temperature distributions behind the nozzle or engine.
\end{abstract}

Key Words: Jet Noise, Scale-model Test, Engine Test, Source Localization, Flow Measurement

\section{Nomenclature}

$D$ : nozzle diameter

EPNdB: effective perceived noise level

$f$ : frequency

$M$ : Mach number

$P$ : pressure

St: Strouhal number

$T:$ temperature

$X$ : position

\section{Subscripts \\ $\mathrm{j}$ : jet \\ $\mathrm{t}$ : total}

\section{Introduction}

Modern commercial jet aircraft contain several types of noise sources in the airframe and engine. The airframe components such as slats, flaps, and landing gears contribute to the total aircraft noise level during approach and landing. The aero-engine (i.e., the power plant of the aircraft) dominates aircraft noise during takeoff under high power settings. Among the engine components, the nozzle, irrespective of whether it is single or coaxial, discharges a high-temperature, high-speed jet to the atmosphere. The aerodynamic process of the high-speed jet is well known to be the origin of jet mixing noise. ${ }^{1,2)}$ The countermeasures against jet noise are higher-bypass-ratio engines and jet noise suppressors. By increasing the bypass ratios of aero-engines, the

(C) 2014 The Japan Society for Aeronautical and Space Sciences.

*Presented at the 2013 Asia-Pacific International Symposium on Aerospace Technology (APISAT-2013), Nov. 20-22, 2013, Takamatsu, Japan. cumulative noise levels have been mitigated by more than 20 EPNdB in past decades. ${ }^{3,4)}$ However, recent stringent noise regulation for civil jet aircraft ${ }^{5)}$ and market pressure require the research institutes and aircraft manufacturers to make further efforts to gain noise margins at lateral and flyover points.

Jet noise suppressors have been studied through experimental and computational approaches. A chevron, consisting of serrations formed at the nozzle end is a successful example in practical use. ${ }^{6-9)}$ Between the neighboring serrations of the chevron nozzle, twisted-pair vortices are excited and promote mixing of the jet with the surrounding flow, which suppresses noise in the rear angles of the engine. The acoustic and aerodynamic performances depend on the geometry and penetration of the serration. A notch, a small dent formed at the nozzle exit, has been studied under collaboration between JAXA and IHI. ${ }^{10-12)}$ A revised type of notched nozzle proved to suppress the jet mixing noise and the higher-frequency noise even along the side. A microjet is also an attractive active suppressor. ${ }^{13-15)}$ The role of the microjet is to generate slight disturbances at the surface of the jet and deform the shear layer. The deformation weakens the shear stress of the downstream jet and prevents the emission of large-scale vortices downstream of the nozzle, which is effective in suppressing broadband peak noise. A claw, composed of sharp-edged parts (i.e., nails), has been proposed as a retractable jet noise suppressor. ${ }^{16,17)}$ The geometry and configuration of the half-edged nail have been improved using computational fluid dynamics (CFD) and scale-model testing. A variable cross-sectional nozzle is also proposed as a low-noise and low-thrust-loss nozzle for supersonic transport. ${ }^{18)}$

It is noted that research and development of these jet 
noise suppressors depend on the measurement techniques. Several types of measurement techniques contribute to better understanding and evaluating the acoustic properties of jet noise suppressors. According to the experience of jet noise experiments during past decades, the authors emphasize three types of measurement. The first one is far-field noise measurement. This is fundamental and the most important measurement. The sound pressure level (SPL) is a direct index that determines the noise suppression effect by the jet noise suppressor. The spectra of SPL, if coupled with other metrics such as scale ratio, flight path, atmospheric conditions, etc., could be presented in the form of effective perceived noise levels (EPNLs). Far-field noise measurement is required to be performed under different conditions, such as scale of nozzle, flow speed, exhaust temperature, and types of noise sources (nozzle or engine). The second one is near-field sound sources (i.e., sound source localization). As aircraft and engines contain several types of noise sources, the necessity for extracting the noise sources concerned is increasing. The source distributions with strength and frequency enable the acoustic engineers to correlate the concerned noise sources with some mechanical or aerodynamic or both causes, and to develop appropriate countermeasures. The last type is to experimentally clarify the flow profiles such as pressure and temperature distributions behind the nozzle or engine. The measured flow profiles are applied to compare with the CFD, evaluation of the mixing enhancement, and noise estimation using an empirical noise model.

With this background, JAXA has dealt with several types of jet noise measurement in the past decade. The primary purpose of this paper is to introduce a form of measurement and its results, and share the technical experience in these measurements with readers. Among the cases of jet noise-related measurement, this paper focuses on three categories: far-field noise measurement in both scale-model tests and static engine tests, sound source localization using a phased-array microphone in both ground test and flight test, and flow profile measurement behind the nozzle or engine. Each case is briefly explained together with the published data.

\section{Jet Noise Measurement}

\subsection{Subscale-model noise test (cold jet)}

The first phase of jet noise testing is carried out with a subscale-model. Fundamental acoustic characteristics and the aerodynamic impact are investigated in anechoic facilities. The ideal subscale-model test should include far-field sound pressure measurement under a simulated heated jet. Measurement of the thrust loss caused by the jet noise suppressors is also desirable. However, there exist technical difficulties to satisfy all of these requirements in one facility. ${ }^{19)}$ JAXA prepared two types of subscale-model noise test setups. One is an unheated jet (i.e., cold-jet rig in an anechoic room) and the other is a heated jet (i.e., hot-jet rig using a model jet engine as a heated gas generator).

The cold-jet rig aims at evaluating the fundamental acoustic property of the newly proposed jet noise suppressors. This rig does not measure the thrust that the nozzle causes. The anechoic room is $4.1 \mathrm{~m}$ in length, 5.7 $\mathrm{m}$ in width, and $3.3 \mathrm{~m}$ in height. Pressurized air is supplied to a settling chamber in the anechoic room. A jet is vertically emitted from the nozzle at the top of the settling chamber into the ambient air. The total pressure inside the settling chamber is regulated via a control valve so that the nozzle pressure ratio (NPR) can be kept constant.

For far-field acoustic measurement, free-field microphones (B\&K 4135) are placed at a $1.5 \mathrm{~m}$ arc centered at the nozzle exit. The distance between the nozzle and each microphone corresponds to 50 times the representative nozzle diameter that is sufficient to assume the far-field considering the model scale and wave length. The radiation angle ranges from $20^{\circ}$ to $90^{\circ}$ relative to the
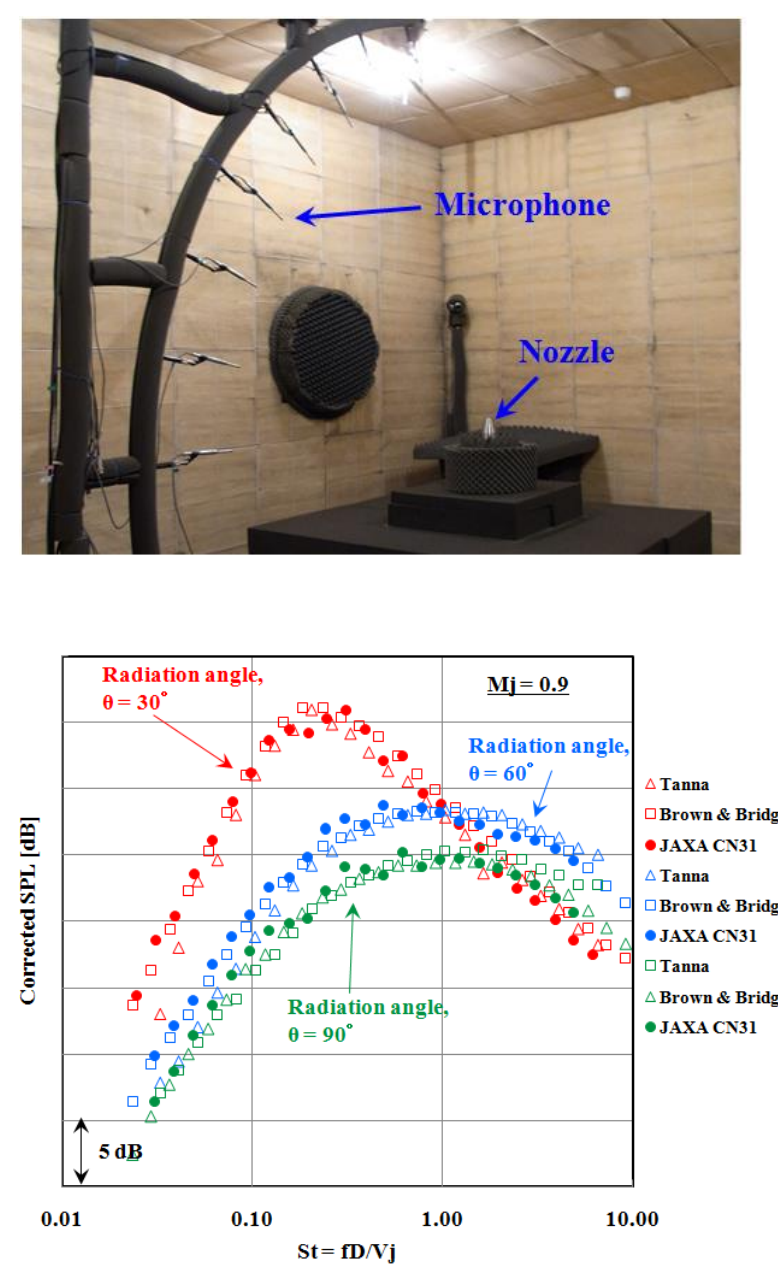

Fig. 1. Anechoic room for the cold jet test (top) and an example of far-field noise measurement (bottom, denoted as JAXA CN31). All spectra are obtained under a subsonic jet from a conical nozzle. Sound pressure levels are corrected with nozzle diameter and distance between the nozzle exit and microphone arc. 


\section{T. ISHII et al.: Overview of Jet Noise Measurement at JAXA}

jet axis. Time signals are, via preamplifiers (B\&K 2669) and signal conditioners (B\&K NEXUS), simultaneously recorded into a high-speed digital recorder (TEAC DS160R) at a sampling rate of $200 \mathrm{kHz}$. The available frequency band is under $80 \mathrm{kHz} .{ }^{19)}$

The anechoic room for the cold-jet test and an example of the cold-jet test results are shown in Fig. 1. The far-field noise spectra are corrected with regard to the nozzle diameter and the radius of the microphone arc. The spectra are compared at radiation angles $30^{\circ}, 60^{\circ}$, and $90^{\circ}$ from the jet at the Mach number of 0.9 . Their spectra agree well with the reference data. ${ }^{20,21)}$

\subsection{Subscale-model noise test (hot jet)}

Another subscale-model noise test is conducted using a
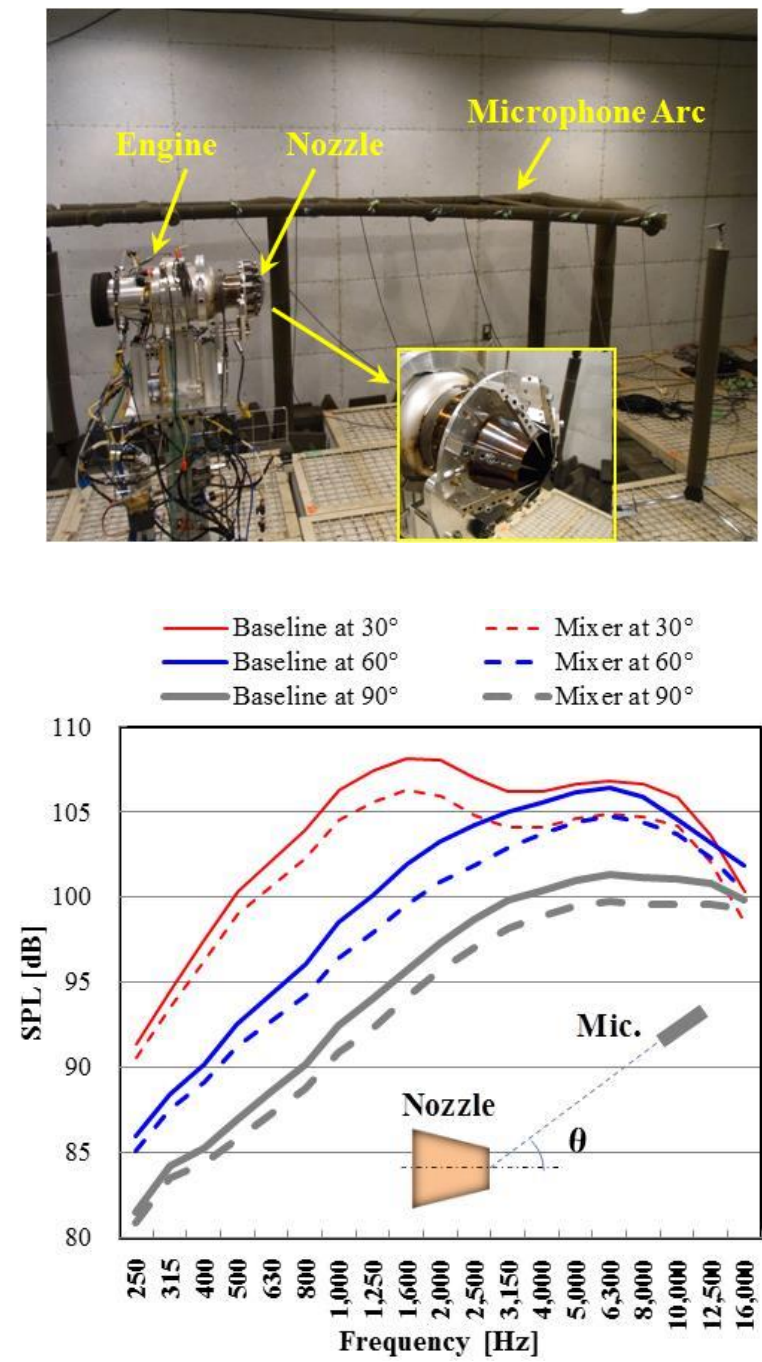

Fig. 2. Hot-jet test setup (top) and an example of far-field noise measurements (bottom) using a baseline conical nozzle and a nozzle with a claw. Spectra at $30^{\circ}, 60^{\circ}$, and $90^{\circ}$ from the jet axis are compared between the baseline (without mixer) and mixer (with claw mixer) measurements. The Mach number of the jet is 0.7 . hot-jet rig, which was newly constructed. This hot-jet test rig is capable of measuring the thrust as well as far-field sound pressure levels. A combination of a model jet engine and an anechoic wind tunnel ${ }^{22,23)}$ enabled noise measurement under heated gas. A turbojet engine with a maximum thrust of 140 to $160 \mathrm{~N}$ is used as a hot gas generator. The aerodynamic data concerned are the pressure and temperature inside the nozzle and inlet duct. The thrust is monitored via a load cell unit placed beneath the engine stand that is mechanically suspended on the base stand. Referring to this engine data, the coefficients regarding the mass flow rate and the thrust are estimated with and without jet noise suppressors.

As for acoustic measurement, free-field microphones are placed at a $2 \mathrm{~m}$ arc centered at the nozzle exit. The amplifiers and high-speed data recorders are similar to those in the cold-jet test. The radiated sound is contaminated by noise components other than jet mixing noise. Therefore, post-processing to eliminate the tones from the compressor, and the tones and broadband noise from the turbine are necessary.

The test setup and an example of noise measurement are presented in Fig. 2. The spectra in the figure were obtained at $30^{\circ}, 60^{\circ}$, and $90^{\circ}$ from the jet axis at the estimated Mach number of 0.7. The spectra indicate noise reduction by a jet noise suppressor (i.e., claw mixer). The broadband peak is suppressed well by mixing enhancement due to the nails attached at the nozzle end. ${ }^{17)}$

\subsection{Noise test with larger-scale engine}

As well as the subscale model tests, a full-scale or larger-scale noise test is required to confirm the practical performance of the jet noise suppressors. To satisfy this requirement, JAXA conducted static engine tests. ${ }^{24,25)}$

A turbojet engine with a nozzle exit diameter of 260 $\mathrm{mm}$ was employed as a jet noise demonstrator. This demonstrator engine was operated in an outdoor environment at JAXA's Noshiro Testing Center. A test stand held the jet engine so that the height of the engine above the ground was kept at $3 \mathrm{~m}$. A tailpipe section was settled between the engine and the nozzle. Pressure and temperature rakes were put inside the tailpipe to monitor the total pressure and total temperature upstream of the nozzle. The engine data, such as thrust, NPR, and engine rotation speed, were fed back to the digital engine controller to operate the engine so that the engine parameters were stabilized. ${ }^{26)}$ 
The radiated noise was recorded by ground microphones at an $18 \mathrm{~m}$ arc centered at the nozzle. A pressure condenser microphone (GRAS-40BP) was inversely installed on a microphone stand with a quarter-inch spacing between the microphone cartridge and a reflective flat plate. This settlement aims at avoiding reflection between the noise source and microphone. The time signals of all the microphones were amplified by a signal conditioner and then digitally recorded by independent data recorders (e.g., National Instrument PXI-Express and OROS OR36). The atmospheric information including pressure, humidity, temperature, and wind speed and direction were recorded simultaneously and referred in order to correct the data. The digital data were recorded at a $51.2 \mathrm{kHz}$ sampling rate via an anti-aliasing filter. The reflection on the microphone stand was corrected in the post-processing.

A picture of the engine noise test and an example of the noise test are shown in Fig. 3. The graph compares the overall sound pressure levels (OASPLs) of a variable nozzle. As the variable structure increases the nozzle exit area, it enlarges the slits between neighboring nozzle parts. The slits generate small disturbances behind them. It is expected that these disturbances weaken shear in jet, and as a result, reduce the average jet velocity. Considering
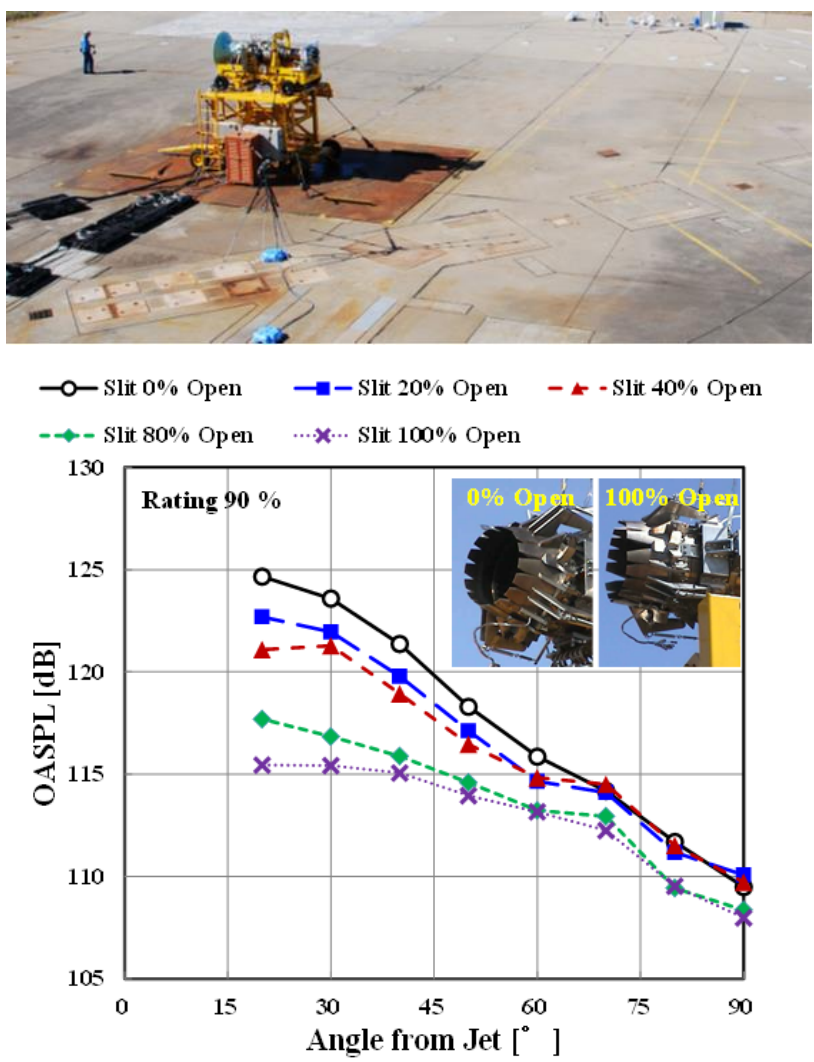

Fig. 3. View of engine noise test (top) and example of the overall sound pressure levels (OASPLs) obtained using a variable nozzle (bottom). The power setting of the engine was set to $90 \%$. The " $100 \%$ open" denotes $10^{\circ}$ angle of the movable parts against jet axis. the dependency of the far-field jet mixing noise on jet velocity, the noise suppression is reasonable. Other jet noise suppressors showed similar noise reduction in the engine test. ${ }^{25,27-29)}$
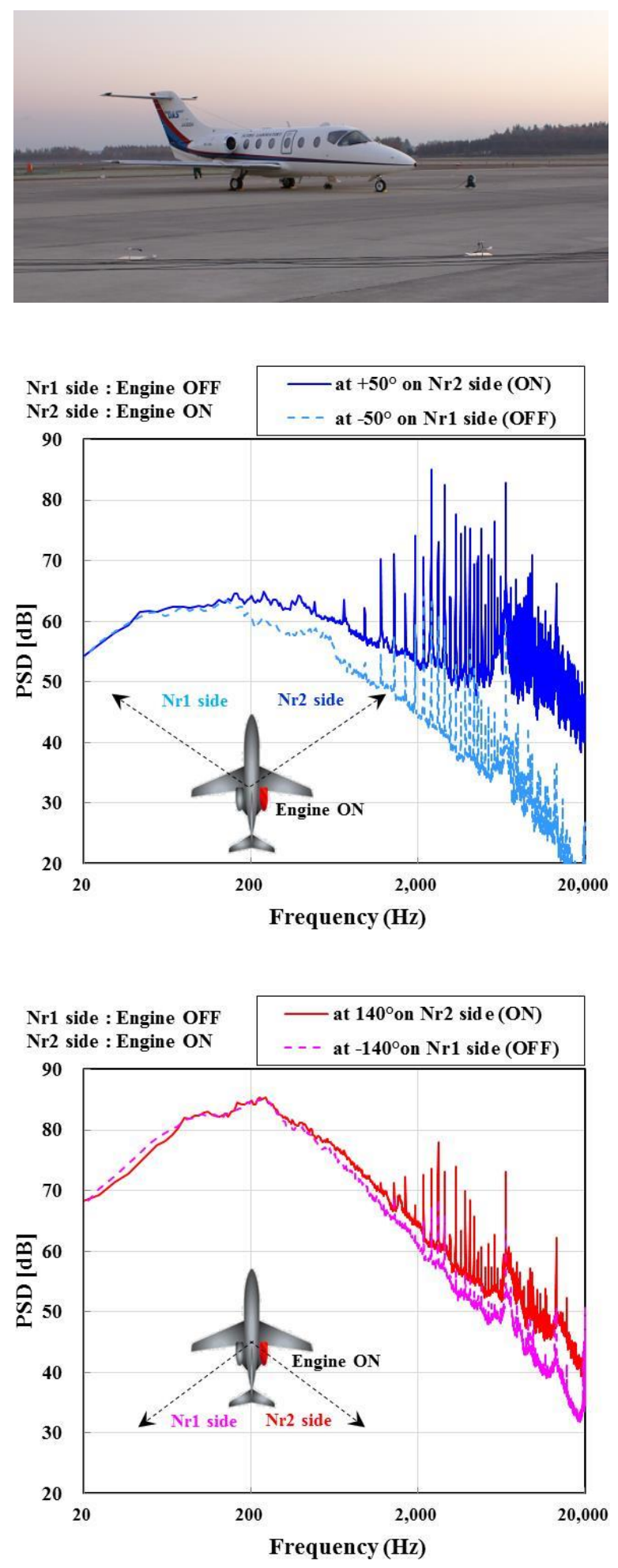

Fig. 4. View of static noise test of the installed engine (top) and the power spectrum densities (PSD) obtained in the far-field of the aircraft. The right-hand engine ( $\mathrm{Nr} 2$ engine) was operated at $90 \%$ rating. The radiation angles from the aircraft nose are $50^{\circ}$ (middle) and $140^{\circ}$ (bottom). 


\subsection{Noise test with installed turbofan engine}

Far-field noise measurement is also possible during ground operation of an aircraft. JAXA conducted the noise test as the first one of the test campaign regarding a low-bypass-ratio turbofan engine that was installed on a jet aircraft. ${ }^{30)}$ The sound source localization and flow profile measurement were carried out in the following test period. The noise measurement, though it was conducted under inlet distortions, provided useful data regarding fans, compressors, combustors, turbines, and nozzle. The data were compared with the empirical noise model mentioned later.

A Mitsubishi MU300, ${ }^{31)}$ a business jet aircraft, was chosen for the test campaign. This aircraft has two Pratt \& Whitney Canada JT15D engines ${ }^{32)}$ at the rear of the fuselage. The aircraft was rigidly stabilized on a hard surface at the Obihiro airport. The engine was operated under predetermined power settings including 75, 80, 90, and $95 \%$ engine rates.

Microphone stands were placed at a $25 \mathrm{~m}$ arc centered
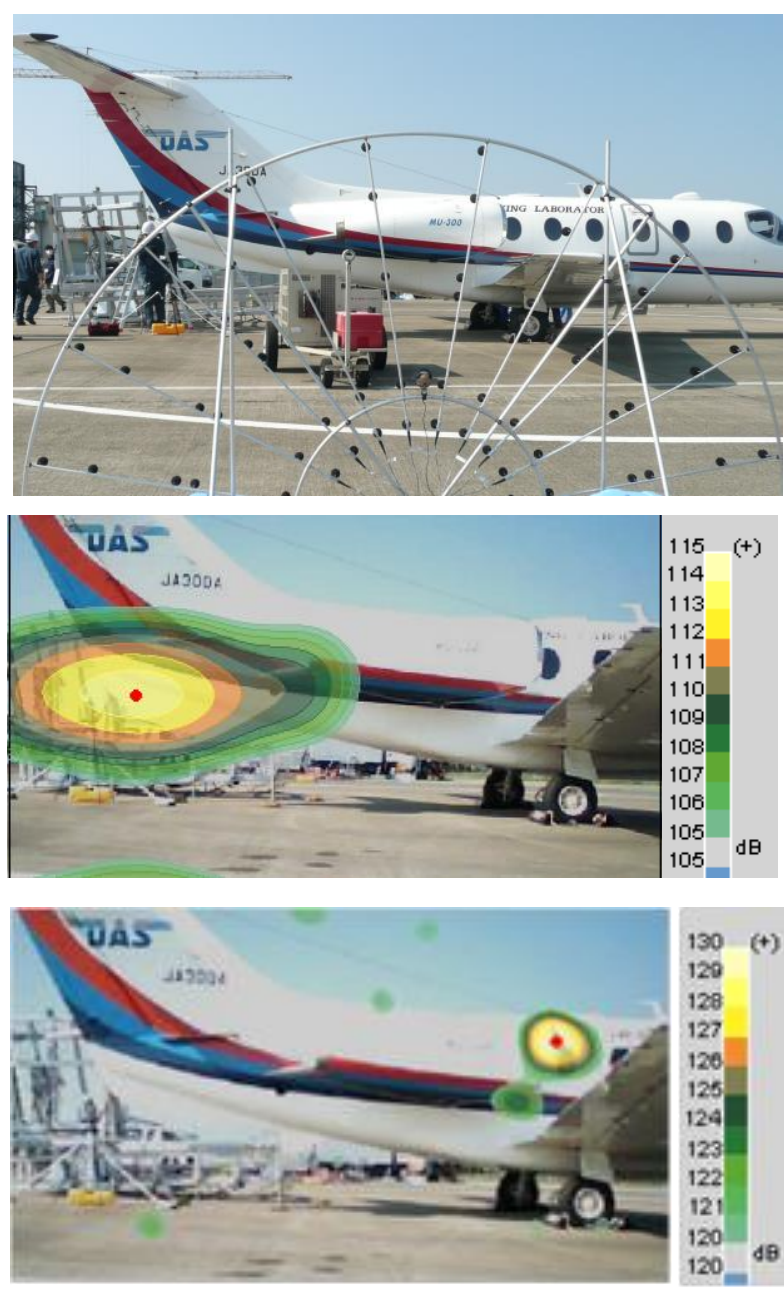

Fig. 5. Half-wheel microphone array placed at the side of the engine (top). The sound source maps in the $1,000 \mathrm{~Hz}$ band under a $95 \%$ engine rate (middle) and in the $3,150 \mathrm{~Hz}$ band (bottom). at the aircraft. Their angular positions began at $10^{\circ}$ relative to the aircraft nose and ended at $160^{\circ}$ with intervals of $10^{\circ}$. The configuration at the microphone stand and the data acquisition system are the same as those in the engine noise test. Time signals were recorded for at least $30 \mathrm{~s}$ for each engine power setting.

Figure 4 shows a picture of the static noise test using the aircraft and the sound spectra measured at the forward and rear directions relative to the engine. ${ }^{30)}$ The engine power setting was $90 \%$. The forward-propagating noise $\left(50^{\circ}\right.$ from nose) at a higher power rate is dominated by the fan tones together with buzz-saw tones. The aft-propagating noise $\left(140^{\circ}\right.$ from nose) indicates that the broadband jet mixing noise is predominant even though the higher-frequency tones remain. The spectra obtained on the opposite side, where the engine was not operated, suggested that the fuselage well disrupted the forward-propagating noise, whereas jet mixing noise is
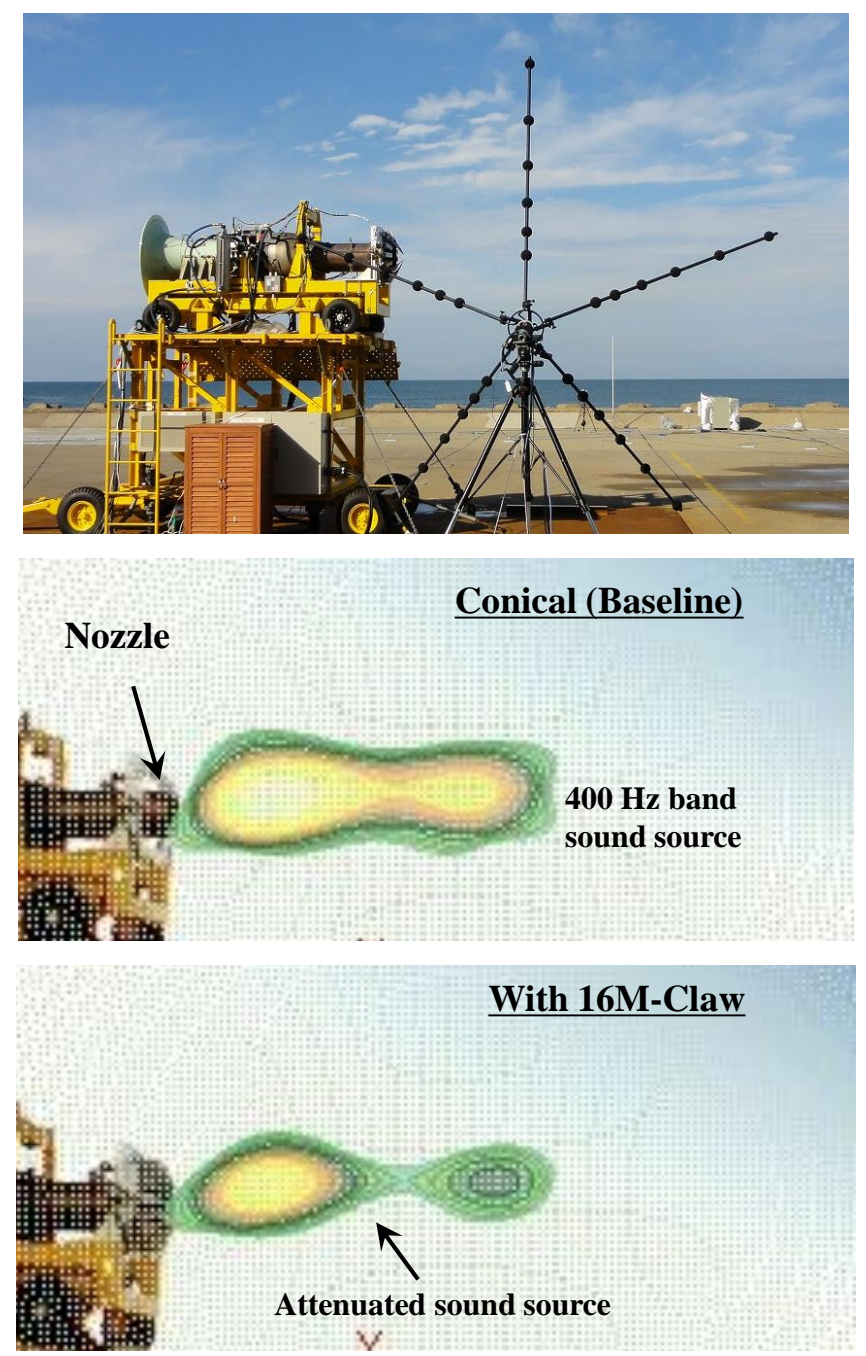

Fig. 6. Pentangular array (Bruel \& Kjaer) applied to the static engine test (top). Examples of source maps around the nozzle (middle: baseline nozzle, bottom: nozzle with claw mixer). The source maps in the $1 / 3$ octave $400 \mathrm{~Hz}$ are compared under an $85 \%$ engine rate. 
little affected by the fuselage.

\section{Sound Source Localization}

\subsection{Sound source localization in static testing}

Sound source localization techniques have rapidly spread worldwide as the attention to aerodynamic sound sources has increased. A phased array microphone system with a multiple-channel data acquisition unit and post-processing shows contours of sound sources at different frequency bands. In the outdoor noise test, the compact structure and quick review function are preferable under the limited test window.

One example is sound source localization in the ground testing of the JT15D engine installed on the MU300 aircraft. ${ }^{30)}$ A half-wheel array of Bruel \& Kjaer (B\&K Type 9712) was placed on the lateral side of the engine (Fig. 5). This 3-m array has 60 microphones on the bars. Frequency-domain beam-forming is available for the frequency range from 315 to $10,000 \mathrm{~Hz}$. Examples of the sound sources in the $1,000 \mathrm{~Hz}$ and $3,150 \mathrm{~Hz}$ bands are plotted in Fig. 5. As for the $1,000 \mathrm{~Hz}$ band, a sound source is distributed over a wide range behind the nozzle. Contrarily, the higher frequency sound source $(3,150 \mathrm{~Hz}$ band) caused by the fan tones is distinct in front of the engine inlet.

Another example is the outdoor noise test on the jet noise suppressor. ${ }^{28,33)} \mathrm{A}$ foldable five-bar array (B\&K pentangular array) has 30 microphones on the bars. Frequencies between $100 \mathrm{~Hz}$ and $5 \mathrm{kHz}$ are available. This array was set parallel to the jet plume, laterally $5.5 \mathrm{~m}$ from the jet axis and $3 \mathrm{~m}$ downstream of the nozzle end. Figure 6 shows the phased array microphones together with the demonstrator engine. The examples of the sound sources with and without the jet noise suppressor made it clear that the suppressor weakened the noise source downstream of the nozzle. As is deduced from the mixing process by the suppressor, the large-scale vortex shedding far downstream of the nozzle was suppressed. This suppressed shedding accounts for the reduced sound pressure level around the broadband peak.

\subsection{Sound source localization in flight test}

The phased array microphone system can also be used for moving sound sources. In the flight test, the phased array microphone is set on the ground and receives the sound waves from the aircraft and engines. The difficulty of sound source localization in the flight test lies in capturing the motion of the object that radiates the sound. In the case of automobiles or trains, which move on a road or a railway, the motion of the object is approximately expected one-dimensional. On the other hand, aircraft, even if flown following some navigation system, flies with a three-dimensional trajectory. In addition, its attitude (i.e., yaw, pitch, and roll angles) affect sound propagation to the ground. Consequently, the phased array microphone in a flight test needs a device to determine the position, speed, and attitude of the aircraft.
Figure 7 presents a picture of the flight test using a model jet airplane and an example of post-processing. A combination of a 72-microphone array with a 16-channel laser sensor array was applied. ${ }^{34)}$ A model aircraft having a length of $4 \mathrm{~m}$ and a width of $3.9 \mathrm{~m}$ was powered by two turbine jet engines, the maximum thrust of which is about $9 \mathrm{~kg}$. The speed passing over the array was around 200 $\mathrm{km} / \mathrm{h}$. Reflective mirrors were attached to the bottom surface of the fuselage in a special pattern. By post-processing the time signals of all the laser sensors, the time, position, and speed of the model aircraft were estimated. The time signals of all the microphones, synchronized with that of the laser sensors, were used to compute the time-domain beam-forming. In the subsequent flight test, an image-processing technique was introduced to improve the accuracy of capturing the moving object: the height, speed, pitch, yaw, and roll of the object. Figure 8 shows a schematic view of the system and examples of the captured images. ${ }^{35)}$ The line-scanning cameras take digital images of the flying object at a high-speed rate.

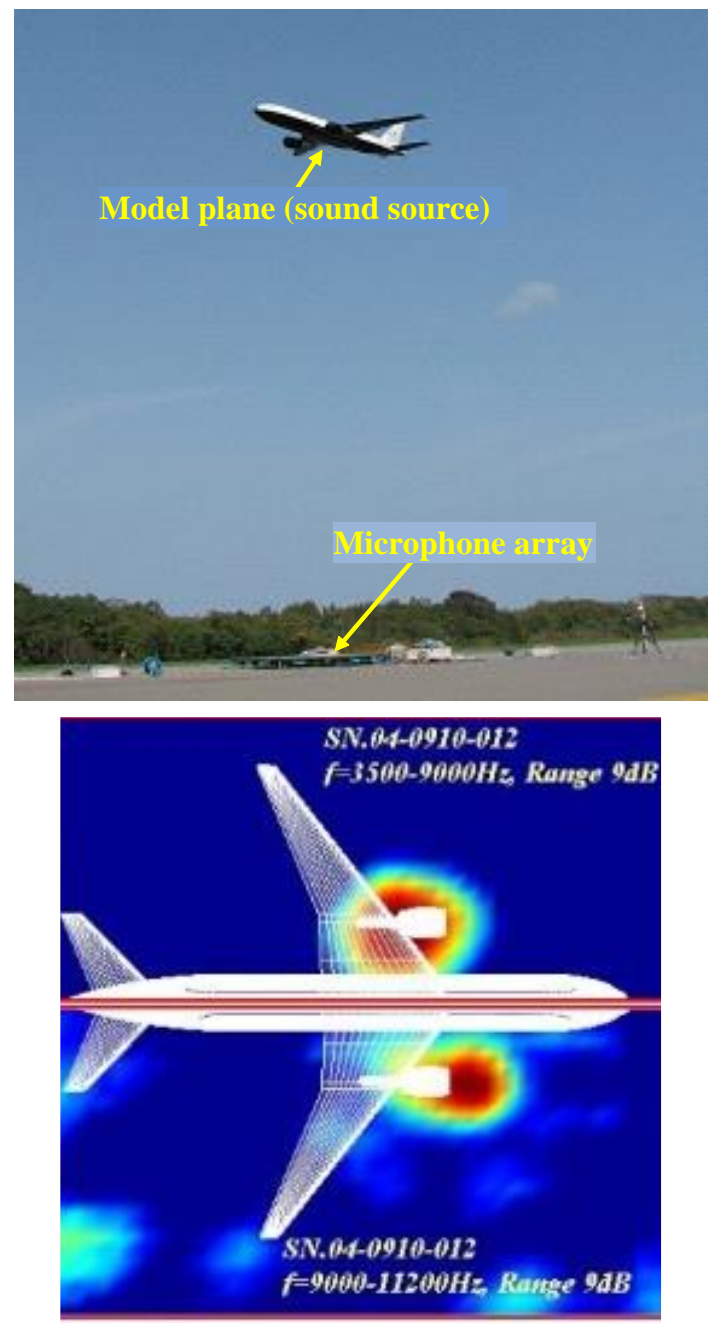

Fig. 7. Flight test using a model jet plane (top) and example of simple beam-forming analysis (bottom). 


\section{T. ISHII et al.: Overview of Jet Noise Measurement at JAXA}

The next phase of flight testing was conducted using a full-scale jet aircraft. ${ }^{36)}$ JAXA and Bruel \& Kjaer Japan collaborated on this measurement. A small practical array system was employed for this flight test (Fig. 9 top). The star-shaped array was composed of nine bars each $6 \mathrm{~m}$ long. Quarter-inch microphones (B\&K 4958) were put inside the bar. The total number of microphones was 108 . The available frequency of the array was $500 \mathrm{~Hz}$ to $5 \mathrm{kHz}$. The time domain tracking delay and sum beam-forming were coupled with de-convolution in the frequency domain. An example of post-processing is shown in the middle of Fig. 9. Sound sources are designated at different parts of the aircraft. At the end of the engine, the sound source by the jet is presented. The wing tip involves a sound source that is caused by the edge drain pipe.

In addition to the compact array system, JAXA applied a larger phased array to the same flight tests. ${ }^{37)}$ This array was designed to be available over a wide range of frequencies. To improve the resolution of the sound source at lower frequencies, the diameter of the array was increased to $50 \mathrm{~m}$ (Fig. 9 bottom). The microphones on the array were classified into three categories to efficiently respond to different frequency bands: low (below $2 \mathrm{kHz}$ ), middle $(1.6 \mathrm{kHz}$ to $5 \mathrm{kHz}$ ), and high (over $3.15 \mathrm{kHz}$ ).
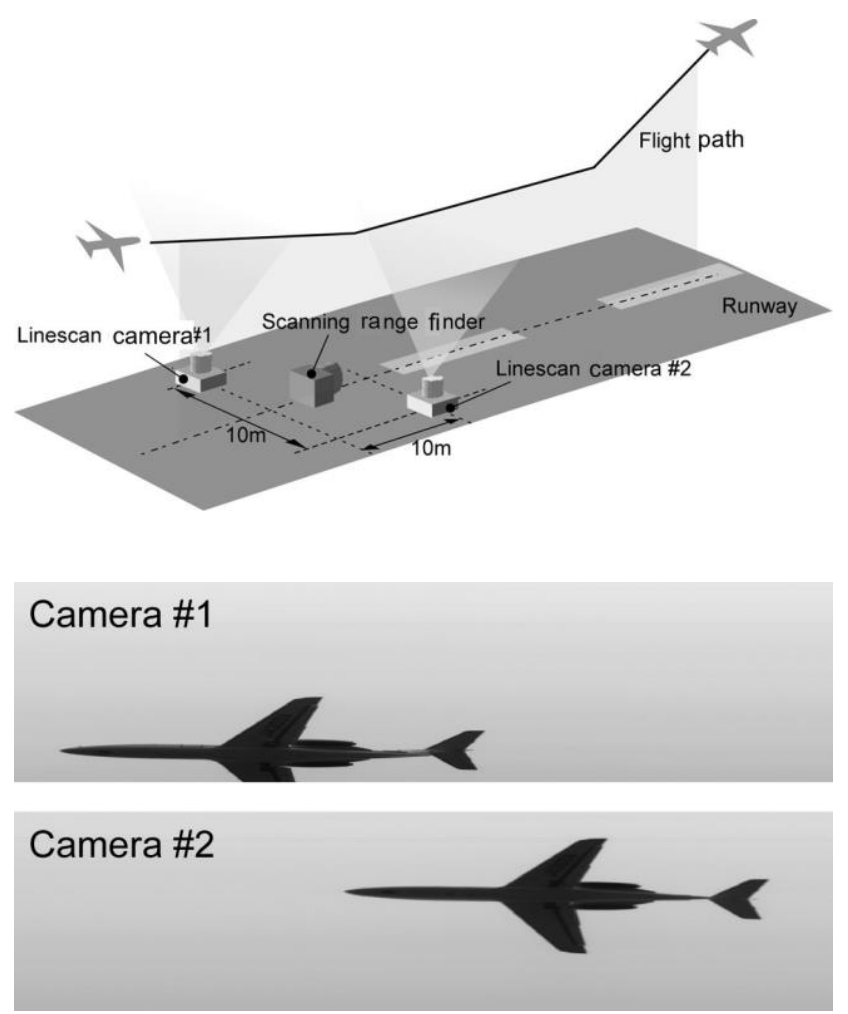

Fig. 8. Schematic of image processing using a line-scanning camera system (top) and the results (bottom)

\section{Flow Profile Measurement}

\subsection{Pressure measurement behind subscale nozzle}

Jet mixing noise source is attributed to the aerodynamic process in a jet. Flow profiles behind the nozzle or engine help understand the acoustic performance of the jet noise suppressors. For the subscale nozzle in the anechoic room,
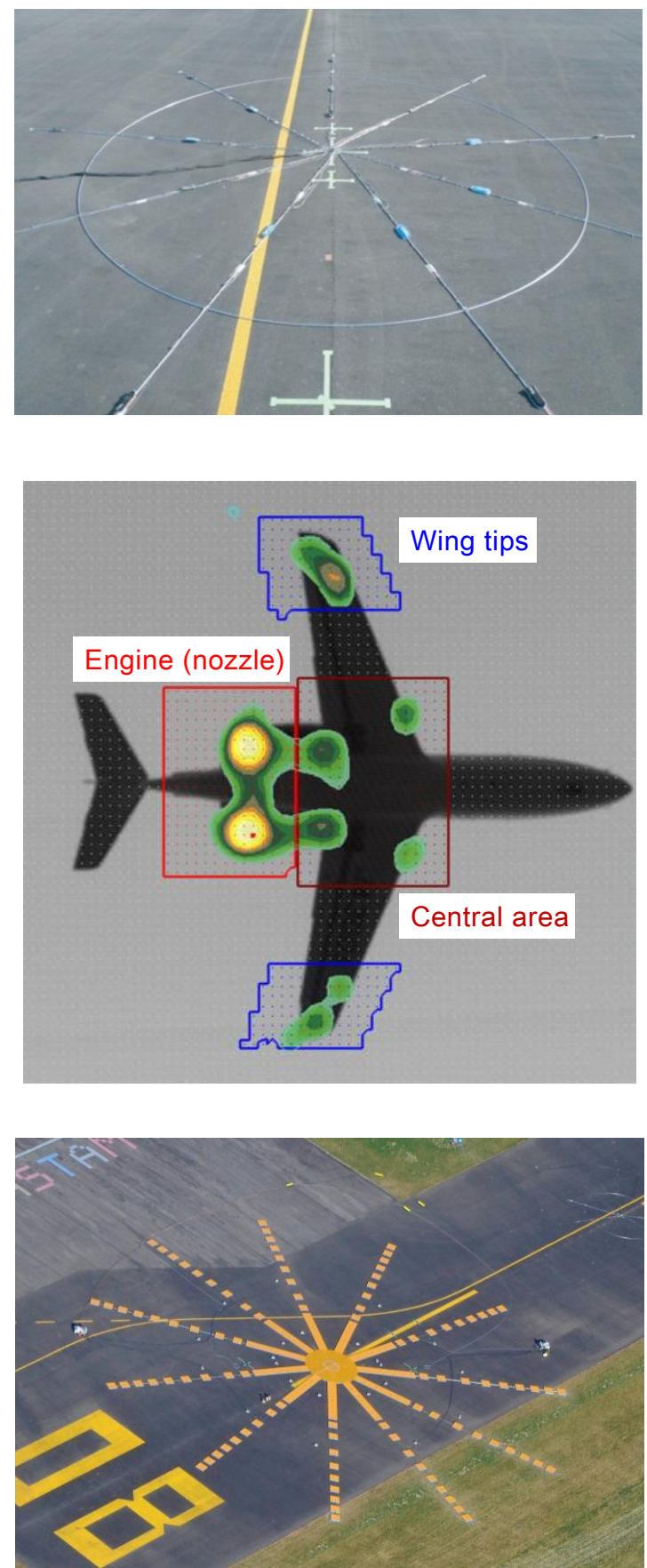

Fig. 9. Phased array microphones used in the flight tests. A small practical array of Bruel \& Kjaer is $12 \mathrm{~m}$ in diameter and composed of 9 bars (top). Example of post-processing obtained by the Bruel \& Kjaer phased array system (middle). An array set up by JAXA is $50 \mathrm{~m}$ in diameter and has 11 bars involving 198 microphones (bottom). 
Trans. JSASS Aerospace Tech. Japan Vol. 12, No. APISAT-2013 (2014)

the total pressure distributions are measured using a pressure rake behind the nozzle. ${ }^{38)}$ A pressure rake with 31 holes is traversed along the jet axis as far as 10 times the nozzle exit diameter (10D). At each axial position, pressure profiles are obtained by rotating the nozzle that is mechanically independent of the settling chamber. The pressure rake and examples of pressure measurements are shown in Fig. 10. An eight-lobed nozzle and a four-slit nozzle both tend to divide the jet plume into several parts or strongly deform the plume. This tendency suggests

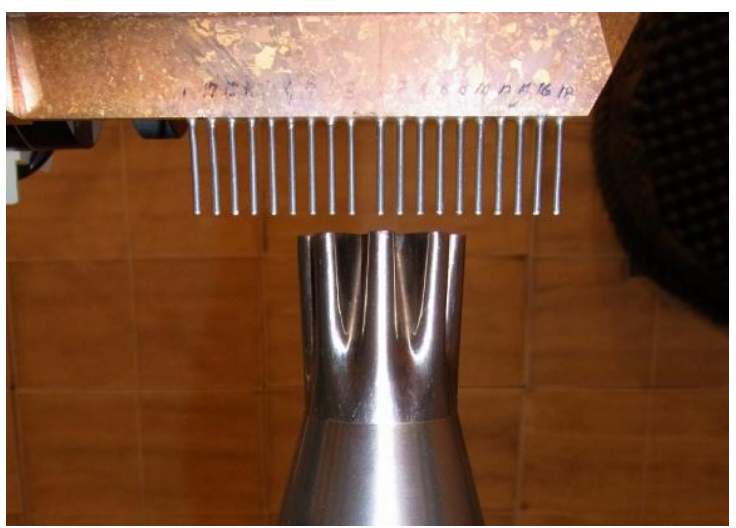

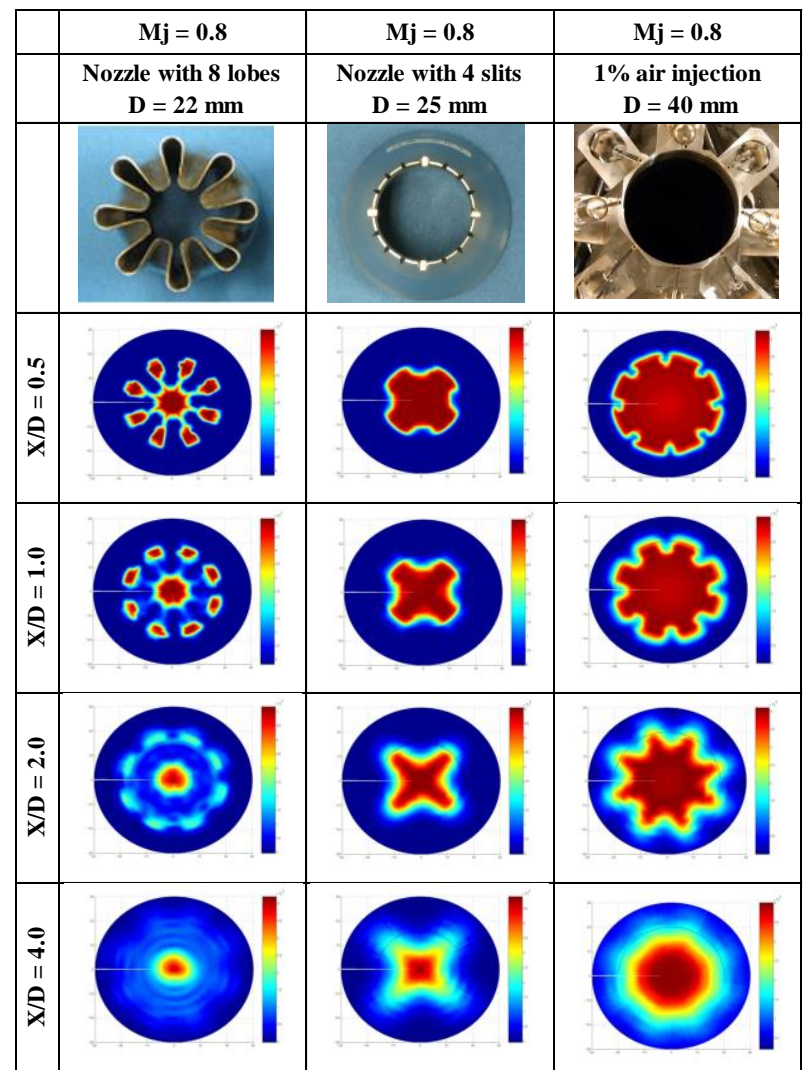

Fig. 10. Flow measurement setup (top) and pressure distributions obtained by a pressure rake downstream of the nozzle (bottom). An eight-lobed nozzle (left), a nozzle with four slits (center), and a nozzle with eight air injectors (right) are compared at different axial positions, $\mathrm{x} / \mathrm{D}=0.5,1.0,2.0$, and 4.0 from the nozzle end
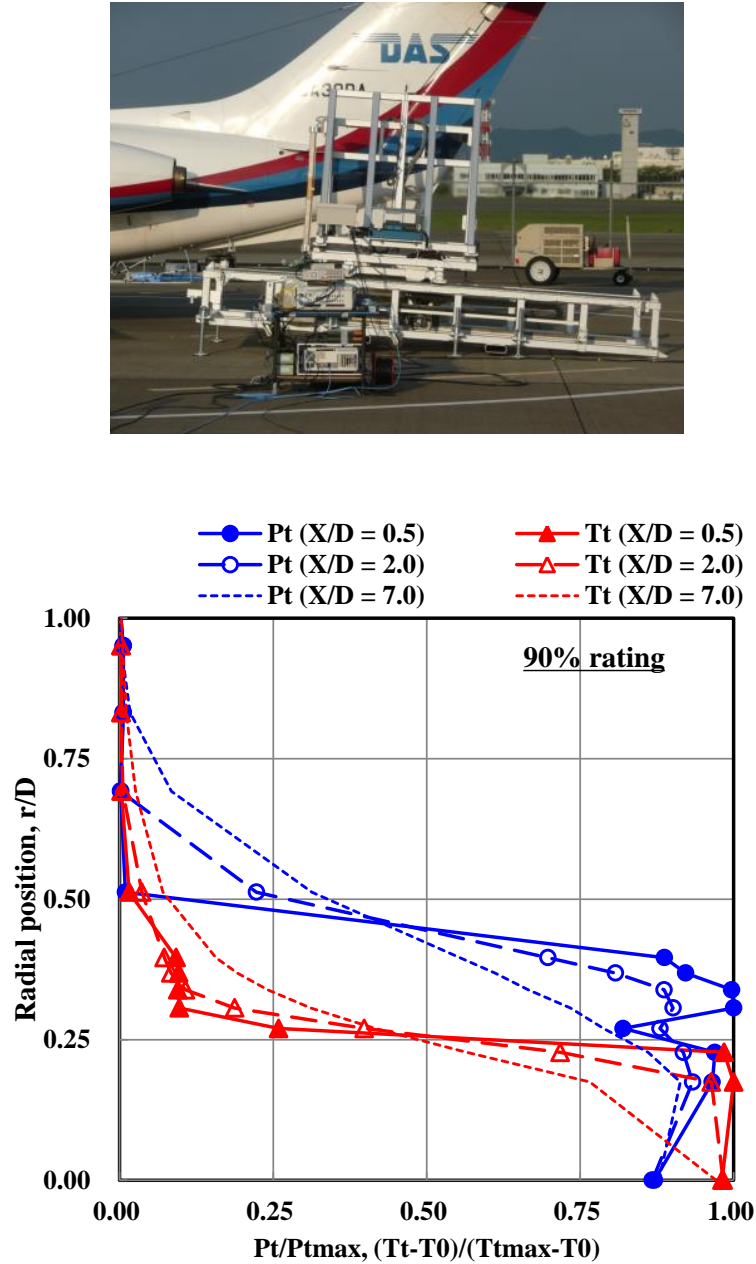

Fig. 11. Flow measurement setup applied to a turbo-jet engine installed on aircraft (top), and example of the pressure and temperature profiles behind the engine (bottom).

\section{- Noise test results - Single-source model - - Multiple-source model}

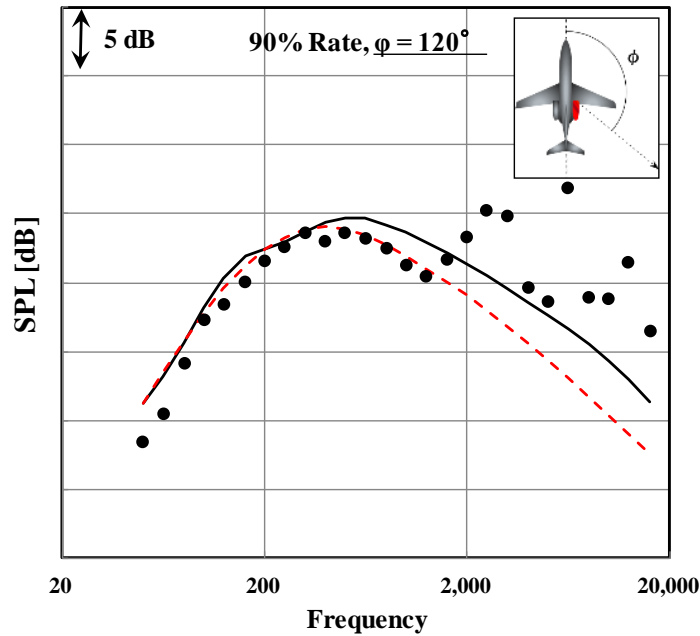

Fig. 12. Comparison of noise test results, single-source model and multiple-source model, for an engine rating of $90 \%$ at $120^{\circ}$ from the nose of the aircraft. ${ }^{41)}$ 
rapid mixing of the core jet with the surrounding flow, which leads to suppression of the broadband peak noise in the far-field. However, this mixing suffers from increasing noise at higher frequencies.

Similar pressure distributions were obtained for the micro-jet, ${ }^{38)}$ notched nozzle, ${ }^{12)}$ and claw mixer. ${ }^{29)}$ These suppressors aim at not rapid mixing, but the small and long-lasting disturbances behind the nozzle. The deformation caused by the micro-jet does not divide the flow field as seen in the lobed mixer. Instead, deformation soon disappears as far as four times the nozzle exit diameter. The experimental results also contribute to the CFD-based revision of the mixing devices. ${ }^{29,39)}$

\subsection{Pressure and temperature measurement behind the jet engine}

Flow measurement using a traversable rake was conducted in the jet engines. A cross-shaped pressure and temperature rake was applied in the static test using a turbojet engine. ${ }^{40)}$ The nozzle diameter $\mathrm{D}$ is $260 \mathrm{~mm}$, and the span of the rake is larger than 2D. Guide rails were placed behind the engine nozzle in order to traverse the rake parallel to the jet. The time signals, including the axial rake positions, were simultaneously recorded via amplifiers. This measurement equipment was adjusted to the turbofan engine installed on the small jet aircraft. ${ }^{41)} \mathrm{A}$ straight rake and its traversing system were aligned with the inclined thrust line of the installed engine (Fig. 11 top). The straight combination rake contains 31 measurement spots. Each spot has pressure and temperature taps covered by a hood. The figure presents the example of the pressure and temperature profiles behind the engine (Fig. 11 bottom).

One application of the direct flow measurement is noise estimation. The flow profiles give jet parameters such as the jet velocities at the core nozzle (primary nozzle) and bypassed nozzle (secondary nozzle). They are used as input for empirical jet noise models, which is useful for quick assessment of the acoustic impact around the engine and aircraft. Many empirical jet noise models have been proposed so far. The representative models are simple single-source models from AIR1905 ${ }^{42)}$ and ARP876, ${ }^{43}$ and a multiple-source model. ${ }^{44,45}$ The multiple-source model assumes four types of mixing processes in the coaxial jet flow, and proposes a source model for each mixing process.

Figure 12 compares the experimental spectra with those estimated using the noise models. ${ }^{41)}$ The spectra on the graph denotes the far-field sound pressure levels under a $90 \%$ power setting. The radiation angle is $120^{\circ}$ from the nose of the aircraft (i.e., in the rear direction of the engine). It is well known that the noise observed around this radiation angle is dominated by broadband peak noise. It is remarkable that the single-source model (solid line) and multiple-source model (dotted line) coincide well with experimental data (solid circle) around the broadband peak frequency. A discrepancy remains between the experiment and noise model results at higher frequencies. This is because of the bypassed fan tones that propagate downstream of the engine.

\section{Conclusion}

Measurement techniques associated with jet mixing noise are essential to research and development of jet noise suppressors for aero-engines. This paper focused on three types of jet noise-related measurement that have been conducted at JAXA. The far-field noise measurement, covering different scales of nozzle from a subscale model to an installed jet engine, is available for the acoustic and aerodynamic performances of jet noise suppressors. The sound source localization using a compact phased array microphone system expands its flexible application to jet noise during flight test. The measurement of flow profiles in static engine testing provided useful data for noise estimation.

\section{Acknowledgments}

The authors thank all of the organizations and people who supported the noise tests mentioned in this paper.

\section{References}

1) Tam, C. K. W.: Jet Noise Generated by Large-Scale Coherent Motion, Aeroacoustics of Flight Vehicles: Theory and Practice, NASA TM-1258, 1(1991), pp. 311-390.

2) Lighthill, M. J.: On sound generated aero- dynamically: 1. General theory, Proc. Roy. Soc. Lon. (A), 211, 1952, pp.564-587.

3) Smith, M. J. T.: Aircraft Noise, Cambridge University Press, 1989.

4) Casalinoa, D., Diozzib, F., Sanninob, R., and Paonessac, A.: Aircraft Noise Reduction Technologies: A Bibliographic Review, Aerospace Science and Technology, 12, 1 (2008), pp. $1-17$.

5) International Civil Aviation Organization: ICAO Environmental Protection Committee Delivers Progress on New Aircraft CO2 and Noise Standards, http://www.icao.int/Newsroom/Pages/ICAO-environmental-pr otection-committee-delivers-progress-on-new-aircraft-CO2-an dnoise-standards.aspx, 2013.

6) Bartlett, P., Humphreys, N., Phillipson, P., Lan, J., Nesbitt, E., and Premo, J.: The Joint Rolls-Royce/Boeing Quiet Technology Demonstrator Program, AIAA2004-2849, 2004.

7) Calendar, B., Gutmark, E., and Martens, S.: Far-field Acoustic Investigation into Chevron Nozzle Mechanisms and Trends, AIAA J., 43, 1(2004), pp. 87-95.

8) Zaman, K. B. M. Q., Bridges, J. E., and Huff, D. L.: Evolution from 'Tabs' to 'Chevron Technology'-a Review, International Journal of Aeroacoustics, 10, 5\&6(2010), pp. 685-710.

9) Oishi, T., Tanaka, N., Ishii, T., Yamamoto, K., and Enomoto, S.: Experimental and Computational Study on Jet Noise Reduction Devices Such as Notched, Chevron and Microjets, ISUAAAT-2012-JP12, 2012.

10) Oishi, T.: Jet Noise Reduction by Notched Nozzle on Japanese ECO-Engine Project, AIAA-2010-4026, 2010.

11) Tanaka, N., Oishi, T., Ooba, Y., Enomoto, S., Yamamoto, K., and Ishii, T.: Experimental and Computational Approach for Jet Noise Mitigation by Mixing Control Devices, ASME-GT2011-45200, 2011.

12) Ishii, T., Oinuma, H., Nagai, K., Tanaka, N., Oba, Y., and Oishi, T.: Experimental Study on a Notched Nozzle for Jet 
Noise Reduction, ASME-GT2011-46244, 2011.

13) Zaman, K. B. M.: Jet Noise Reduction by Microjets - A Parametric Study, AIAA-2009-3129, 2009.

14) Okada, R., Watanabe, T., Uzawa, S., Himeno, T., and Oishi, T.: Influence of Microjet Injection on Supersonic Jet Noise and Flow Field, ASME GT2011-46150, 2011.

15) Tanaka, N., Oishi, T., Piccin, O., Gely, D., Yamamoto, K., and Enomoto, S.: Jet Noise Reduction Using Microjet Configurations Experimental Characterization In CEPRA19 Anechoic Wind Tunnel, AIAA-2012-2300, 2012.

16) Nakamura, S., Ishii, T., Oinuma, H., and Ishikawa, H.: Jet Noise Reduction by the Projected Device Installed in the Nozzle Downstream, JSME-2011 Annual Conference, J091033, 2011 (in Japanese).

17) Ishii, T., Oinuma, H., Nagai, K., and Tagashira, T.: Research on Mixing Devices for Jet Noise Reduction, IGTC2011-0207, 2011.

18) Akatsuka, J., Watanabe, Y., and Ishii, T.: Jet Noise Reduction of Supersonic Aircraft by Variable Area Nozzle, Aircraft Symposium 2013, 2E10, 2013.

19) Ishii, T., Oinuma, H., and Nagai, K.: Scale-Model Tests of Jet Noise, JAXA-RM-13-003, 2013 (in Japanese).

20) Tanna, H. K., Dean P. D., and Burrin, R. H.: The Generation and Radiation of Supersonic Jet Noise, Part III, Turbulent Mixing Noise Data, AFAPL-TR-76-65, 1976.

21) Brown, C., and Bridges, J.: Small Hot Jet Acoustic Rig Validation, NASA/TM-2006-214234, 2006

22) Omiya, S., Sakai, H., Wada, K., Oinuma, H., Ishii, T., and Kaneko, S.: Noise and Aerodynamic Measurement of Heated Jet Using a Small Jet Engine, 41st Gas Turbine Society of Japan Annual Meeting, B-9, 2013 (in Japanese).

23) Ishii, T., Tanaka, N., Oinuma, H., and Oishi, T.: Hot-Jet Noise Test of a Revised Notched Nozzle, ASME-GT2012-69507, 2012.

24) Ishii, T., Tanaka, N., Oinuma, H., Nakamura, S., and Ishii, Y.: Outdoor Noise Test of Revised Notched Nozzle, Internoise-2012-706, 2012.

25) Ishii, T., Tanaka, N., Oishi, T., and Ishii, Y.: Noise Test of Revised Notched Nozzle Using a Jet Engine, ASME-GT2013-94833, 2013.

26) Tagashira, T., Mizuno, T., Satake, T., Sugiyama, N., and Nakata, Y.: Application of Model-Based Control for JAXA's Engine Test, IGTC-2011-0240, 2011.

27) Ishii, T., Oinuma, H., Nagai, K., Mizuno, T., Futamura, H., and Oishi, T.: Outdoor Noise Test of a Turbojet Engine, JSME Annual Meeting 2009 (2), 2009, pp. 261-262 (in Japanese).

28) Ishii, T., Oinuma, H., Nagai, K., Nakamura, S., and Ishii. Y.: Experimental Study of a Claw Mixer, AIAA-2012-2301, 2012.

29) Ishii, T., Enomoto, S., Nakamura, S., and Ishikawa, H.: Jet Flow Control using a Claw Mixer, ICJWSF2013-1172, 2013.

30) Ishii, T., Oinuma, H., Nagai, K., Yokoyama, Y., Yamamoto, K., Tagashira, T., Ishii, Y., and Tanabe, K.: Acoustic Measurement of a Turbofan Engine Installed on a Jet Plane,
Internoise-2011-386369, 2011.

31) FAA, Type Certificate Data Sheet, A14SW, 1998

32) FAA, Type Certificate Data Sheet, E1NE, 1981

33) Ishii, T., Tanaka, N., Oishi, T., and Ishii, Y.: Engine Noise Test of Notched Nozzle, Journal of the Gas Turbine Society of Japan, 41, 5(2013), pp.408-413 (in Japanese).

34) Ishii, T., Kazawa, J., Oinuma, H., Nagai, K., Yamamoto, K., Saiki, K., and Nozaki, O.: Research on Noise Reduction in th Clean Engine Project, Aeronautical and Space Sciences Japan, 56, 659(2008), pp.322-328 (in Japanese).

35) Nagai, K., Oinuma, H., and Ishii, T.: Trajectory Measurement of Jet Aircraft Using Dual Line-scan Cameras, JSME-2010 Annual Conference, G1000-1-5, 2010 (in Japanese).

36) Hald, J., Ishii, Y., Ishii, T., Oinuma, H., Nagai, K., Yokokawa, Y., and Yamamoto, K.: High-resolution Fly-over Beamforming Using a Small Practical Array, AIAA-2012-2229, 2012.

37) Yokokawa, Y., Ura, H., Nagai, K., Oinuma, H., Uchida, H., Yamamoto, K., and Ishii, T.: Improvement of a Noise Source Localization Technique for Aircraft Flyover Test, Aircraft Symposium 2012, 3B01, 2012 (in Japanese).

38) Ishii, T., Oinuma, H., Nagai, K., Tanaka, N., Oba, Y., and Oishi, T.: Jet Noise Suppression by Mixing Control Devices (in Japanese), 38th Gas Turbine Society of Japan Annual Meeting, B-22, 2010.

39) Enomoto, S., Yamashita, K., and Ishii, T.: Large-Eddy Simulation of Jet Flow with a Noise Suppression Device, Aerospace Numerical Simulation Symposium 2012, 2E14, 2012 (in Japanese)

40) Mizuno, T., Ishii, T., Komeda, A., Tagashira, T., Futamura, H., and Koh, M.: The 4th Open-air Field Engine Tests, JAXA-RM-08-016, 2008 (in Japanese).

41) Ishii, T., Okai, K., and Nakamura, S.: Ground Tests of an Installed Jet Engine, ISABE-2013-1319, 2013.

42) SAE: Society of Automotive Engineers "Gas Turbine Coaxial Exhaust Flow Noise Prediction", Aerospace Information Report AIR-1905, 1985.

43) SAE: Society of Automotive Engineers "Gas Turbine Jet Exhaust Noise Prediction", Aerospace Recommended Practice ARP-876C, 1985

44) Fisher, M. J., Preston, G. A., and Bryce, W. D.: A Modelling of the Noise from Coaxial Jets, Part 1: With Unheated Primary Flow, Journal of Sound and Vibration, 209 (1998), pp.385-403.

45) Fisher, M. J., Preston, G. A., and Mead, C. J.: A Modelling of the Noise from Coaxial Jets, Part 2: With Heated Primary Flow, Journal of Sound and Vibration, 209 (1998), pp.405-417. 